\title{
The Impact and Successes of a Paediatric Endocrinology Fellowship Program in Africa
}

\author{
Gordon Otieno Odundo, ${ }^{1}$ Thomas Ngwiri, ${ }^{1}$ Olivia Otuoma, ${ }^{2}$ Paul Laigong, \\ Renson Mukhwana, ${ }^{1}$ Mary Slessor Limbe, ${ }^{4}$ and Nadia Musimbi Chanzu ${ }^{5}$ \\ ${ }^{1}$ Gertrude's Children's Hospital, P.O. Box 42325, Nairobi 00100, Kenya \\ ${ }^{2}$ Gertrude's Hospital Foundation, Gertrude's Children's Hospital, P.O. Box 42325, Nairobi 00100, Kenya \\ ${ }^{3}$ Department of Paediatrics and Child Health, University of Nairobi, P.O. Box 460, Nairobi 00202, Kenya \\ ${ }^{4}$ Department of Paediatrics and Child Health, Aga Khan University, P.O. Box 30270, Nairobi 00100, Kenya \\ ${ }^{5}$ Institute of Child Health and Research, Gertrude's Children's Hospital, P.O. Box 42325, Nairobi 00100, Kenya
}

Correspondence should be addressed to Gordon Otieno Odundo; godundo@gerties.org

Received 28 October 2015; Accepted 24 December 2015

Academic Editor: Franco Veglio

Copyright (C) 2016 Gordon Otieno Odundo et al. This is an open access article distributed under the Creative Commons Attribution License, which permits unrestricted use, distribution, and reproduction in any medium, provided the original work is properly cited.

Background. The prevalence and distribution of endocrine disorders in children in Africa are not well known because most cases are often undiagnosed or diagnosed too late. The awareness of this led to the launch of the Paediatric Endocrinology Training Center for Africa (PETCA) designed to improve quality and access to health care by training paediatricians from Africa in paediatric endocrinology. Methods. The fellowship is undertaken over an 18-month period: six months of clinical and theoretical training in Kenya, nine months of project research at the fellow's home country, and three months of consolidation in Kenya. Upon completion, certified paediatricians are expected to set up centers of excellence. Results. There have been two phases, phase I from January 2008 to October 2012 and phase II from January 2012 to April 2015. Fifty-four fellows from 12 African countries have been certified, 34 (phase I) and 20 (phase II). Over 1,000 patients with wide ranging diabetes and endocrine disorders have been diagnosed and treated and are being followed up at the centers of excellence. Conclusion. The successes of the PETCA initiative demonstrate the impact a capacity building and knowledge transfer model can have on people in resource-poor settings using limited resources.

\section{Introduction}

Paediatric endocrinology relates to the diagnosis, management, and treatment of diseases of the endocrine system in children and adolescents [1]. These include diabetes, disorders of growth, thyroid function, adrenals and sexual development, obesity, and related complications as well as endocrine cancers [1-7]. The prevalence rates of disorders linked to paediatric endocrinology are underappreciated especially in low and middle-income countries (LMICs), due to lack of specialized screening facilities and lack of trained health professionals to diagnose and manage these diseases $[8,9]$. Consequently in Africa, many children die undiagnosed, or if diagnosed they often do not receive qualified and sufficient treatment at the hospital. Some may subsequently die because the family cannot afford long-term medication.
In addition, tertiary facilities and trained personnel for paediatric diabetes and other endocrine diseases had been virtually nonexistent. Therefore, there is need to put in place programs addressing the two key barriers to care for children with endocrine disorders in Africa: capacity building and access to treatment.

Kenya is one of the fastest growing nations in the world, and children under the age of 18 years represent $53 \%$ of the population [10]. The annual growth rate of Kenya's child population is $2.2 \%$ and every child born in Kenya has a right to the highest attainable standards of healthcare encompassing five key parameters of availability, accessibility, affordability, acceptability, and quality [11]. Despite this, child mortality rates in Kenya remain unacceptably high. Estimates indicate that there are 106,000 child deaths every year with an under five-mortality rank of 33 [12]. Part of this is due 
to lack of specialized paediatric services and lack of trained health professionals including paediatric endocrinologists. Until the year 2007, Kenya had only one (1) paediatric endocrinologist. Today there are eight (8) board certified paediatric endocrinologists and of these, seven (7) are graduates of the Paediatric Endocrinology Training Centre for Africa (PETCA). PETCA was launched in 2007 in Nairobi, Kenya, with a mission to provide and maintain high quality training, research, and clinical practice in the endocrinology subspecialty to paediatricians from all over sub-Saharan Africa. Being one of a kind in Africa the PETCA initiative has been able to achieve great success and have a wide reach despite the limited resources available. The programme is run at the Gertrude's Children's Hospital, Kenya, in partnership with the University of Nairobi, Kenyatta National Hospital, and the Aga Khan University Hospital, Nairobi.

Gertrude's Children's Hospital is the longest serving paediatric health institution in East and Central Africa. Established in 1947, the hospital is dedicated to providing care and treatment exclusively to children. Gertrude's has a main hospital campus located in Muthaiga and various satellite clinics across the country. Over the years, the hospital has witnessed a dramatic expansion and now provides a total of over 300,000 visits annually. Many of these hospital visits are at the various local satellite clinics and are focused mainly on the provision of primary care to children. With the increase in outpatient attendees and inpatient admissions and vast expansion of its network, Gertrude's Children's Hospital was well placed to understand and set out to address the urgent need for paediatric specialists in Africa. This led to the launch of PETCA, a fellowship program which specifically aims to (1) equip paediatricians in Africa with the knowledge and skills to diagnose and manage childhood diabetes and other endocrine disorders and (2) facilitate the establishment of comprehensive centers of excellence, specializing in paediatric diabetes and endocrinology across sub-Saharan Africa. Here we report on the successes of the PETCA program, which will ultimately translate to the improvement of the quality and access to specialized healthcare to all children in sub-Saharan Africa.

\section{Methods}

2.1. PETCA Initiative. The Paediatric Endocrinology Training Center for Africa (PETCA) is a joint initiative of the Gertrude's Children's Hospital, Aga Khan University Hospital, Kenyatta National Hospital, University of Nairobi Department of Child Health, International Society for Paediatric and Adolescent Diabetes (ISPAD), and the European Society of Paediatric Endocrinology (ESPE). The program activities started running in January 2008 supported by funding from the World Diabetes Foundation.

2.2. Training Centre. The main training site is the Gertrude's Children's Hospital in Nairobi, Kenya, an institution dedicated to the provision of care and treatment exclusively to children. The hospital operates a busy inpatient unit and is building a model of outreach into the wider community.
2.3. Program Fellows. Fellows are candidates who already have National Medical Board recognition of specialist training in paediatrics in their home countries and for the PETCA program; they are recruited through a competitive process. Announcement and invitation for applications are made through regional medical associations, academic institutions, and tertiary hospitals in Sub-Saharan Africa countries. Applications are processed by the local faculty sitting in Kenya which ensures that equal opportunities are given to all regardless of age, gender, and race.

2.4. Fellowship Program Design. The fellowship is undertaken over an 18-month period, which begins with six (6) months of clinical and theoretical training in Kenya, nine (9) months of project research at the fellow's home country, and three (3) months consolidation in Kenya. Training comprises didactic sessions covering the length and breadth of paediatric endocrinology and diabetes, lectures and journal clubs, clinical teaching in the hospital clinics, and bedside as well as specific courses in research, leadership, and management.

2.5. Program Faculty. Tutorship was initially offered exclusively by ESPE and ISPAD international tutors. However, with the goal of self-sustainability the tutorship was later taken up increasingly by the local faculty, many of them alumni of the center. On completion, certification of the PETCA fellowship is by ESPE. The certified paediatricians are then expected to set up Centers of Excellence in their home countries and/or strengthen existing centers.

2.6. Role of Funding Source. The funding source had no role in the study design; in collection, analysis, and interpretation of data; in the writing of the report; and in the decision to submit the paper for publication.

\section{Results}

Since the launch of PETCA in 2008, there have been two successful phases, phase one which commenced in January 2008 through to October 2012 and phase two which started in January 2012 and was on until April 2015. Fifty-four (54) fellows have been certified: 34 (phase one) and 20 (phase two). The training program aims to include fellows from all regions in Africa: East, West, North, and South Africa. The fellows were from 12 African countries: Botswana, Congo, Ethiopia, Ghana, Kenya, Mauritius, Nigeria, Rwanda, Sudan, Tanzania, Uganda, and Zambia (Table 1).

During the PETCA fellowship, the fellows screened and treated paediatric patients who presented with a wide range of endocrine disorders including diabetes mellitus, obesity, stunted growth and development, pituitary disorders, failure to thrive, and thyroid disorders. These were patient referrals from paediatricians and general practitioners at the Gertrude's Children's Hospital outpatient department and from outreach activities including school screening drives. Initial patient enrollment was low due to lack of awareness and publicity in Kenya on the establishment of clinics in the three participating hospitals. Once this was done through 
TABLE 1: Number of fellows trained from the PETCA initiative during phases one and two (January 2008-April 2015).

\begin{tabular}{|c|c|c|c|}
\hline \multirow{3}{*}{ Country } & \multicolumn{2}{|c|}{ Number of fellows } & \multirow{3}{*}{ Tota } \\
\hline & Phase one (complete) & Phase two (complete) & \\
\hline & January 2008-October 2012 & January 2012-April 2015 & \\
\hline (1) Botswana & 2 & - & 2 \\
\hline (2) Congo & - & 1 & 1 \\
\hline (3) Ethiopia & 1 & - & 1 \\
\hline (4) Ghana & 1 & - & 1 \\
\hline (5) Kenya & 6 & 3 & 9 \\
\hline (6) Mauritius & - & 1 & 1 \\
\hline (7) Nigeria & 11 & 4 & 15 \\
\hline (8) Rwanda & - & 1 & 1 \\
\hline (9) Sudan & 5 & 7 & 12 \\
\hline (10) Tanzania & 6 & - & 6 \\
\hline (11) Uganda & 2 & 2 & 4 \\
\hline (12) Zambia & - & 1 & 1 \\
\hline Total & 34 & 20 & 54 \\
\hline
\end{tabular}

TABLE 2: Number of patients screened and treated during the PETCA fellowship from 2008 to 2015.

\begin{tabular}{|c|c|c|c|c|c|c|c|}
\hline Year & Diabetes & Obesity & Stunted development & Pituitary & Failure to thrive & Thyroid disorders & Total \\
\hline 2008 & 77 & 10 & 10 & 8 & 2 & 1 & 108 \\
\hline 2009 & 154 & 36 & 26 & 15 & 15 & 0 & 246 \\
\hline 2010 & 8 & 9 & 5 & 1 & 11 & 3 & 37 \\
\hline 2011 & 141 & 46 & 22 & 11 & 19 & 5 & 244 \\
\hline 2012 & 98 & 45 & 13 & 16 & 32 & 7 & 211 \\
\hline 2013 & 69 & 15 & 19 & 21 & 17 & 4 & 145 \\
\hline 2014 & 112 & 26 & 19 & 14 & 16 & 9 & 196 \\
\hline 2015 & 132 & 33 & 13 & 18 & 15 & 1 & 212 \\
\hline Total & 791 & 220 & 127 & 104 & 127 & 30 & 1399 \\
\hline
\end{tabular}

various scientific meetings and trainings, the numbers have increased tremendously. To date, a total of 1,399 patients have been screened and treated since the launch of PETCA in 2008 (Table 2).

On completion of the PETCA training, all fellows are expected to return to their home countries and establish or strengthen existing endocrinology clinics. Eight (8) clinics have been strengthened. These are located in Kenya, Tanzania, and Sudan and 23 clinics have been established across eight (8) countries across Africa, all dedicated to the paediatric endocrinology subspecialty (Table 3 ).

Additional achievements of PETCA include (1) the initiation of the "Growth in Practice" (GIP) and "Diabetes in Practice" (DIP) training courses which are conducted with an aim of sensitizing paediatricians, nurses, and nutritionists on taking and interpreting growth measurements correctly. The healthcare workers are also trained on how to link these indices to paediatric endocrinology disorders and diabetes. More than one hundred healthcare workers have undertaken these courses to allow for the provision of high quality care closer to where patients live. (2) The fellows are also active in marking the World Diabetes Day in collaboration with the Diabetes Kenya Association. (3)
Media coverage on PETCA has resulted in increased referrals and some patients have been adopted under the needy cases for support (http://www.gertrudeshospitalfoundation.org/). (4) Through partnership with the "Changing Diabetes in Children" initiative, PETCA alumni in Kenya, Uganda, and Tanzania have rolled out a training program known as the Changing Diabetes in Children (CDiC) program for health workers in lower level health facilities located in Nakuru, Nyeri, Mombasa, Malindi, Embu, Kisii, Kakamega, Mombasa, and Nairobi's Mama Lucy Hospital in Kenya. (5) There is increased access to essential endocrine drugs at these nine $\mathrm{CDiC}$ centers, where they provide free insulin, glucometers, glucose strips, and hemoglobin Alc (HbAlc). Furthermore, hydrocortisone tablets are now freely available and thyroxine is part of the government hospital kit provided at the Kenyatta National Hospital. (6) As a result of the success of PETCA in Nairobi, a similar program, PETCAWest Africa, was launched in Lagos, Nigeria, in 2013 to expand training opportunities for paediatricians in West Africa. (7) The program has benefitted from free genetic analysis that is done in Exeter, United Kingdom, for all countries if the patient (child or adult) with diabetes has had an onset before the age of six months. (8) There are currently 
TABLE 3: Clinics strengthened and established by graduates of the PETCA initiative.

\begin{tabular}{|c|c|}
\hline \multicolumn{2}{|r|}{ Strengthened clinics } \\
\hline Country & Institution \\
\hline Kenya & Kenyatta National Hospital \\
\hline \multirow{2}{*}{ Tanzania } & Kilimanjaro Christian Medical Centre \\
\hline & Muhimbili National Hospital \\
\hline \multirow{4}{*}{ Sudan } & Abu Se'id Paediatric Hospital \\
\hline & University of Gezira Teaching Hospital \\
\hline & Ministry of Health \\
\hline & $\begin{array}{l}\text { Fedail Hospital, Khartoum } \\
\text { Gaafar Ibnauf Specialised Children's Hospital }\end{array}$ \\
\hline \multicolumn{2}{|r|}{ Established clinics } \\
\hline Country & Institution \\
\hline \multirow{4}{*}{ Kenya } & Gertrude's Children's Hospital \\
\hline & Aga Khan University Hospital \\
\hline & Thika Level 5 District Hospital \\
\hline & Machakos Level 5 District Hospital \\
\hline \multirow{8}{*}{ Nigeria } & Federal Medical Centre, Gombe \\
\hline & Benin Teaching Hospital \\
\hline & University Teaching Hospital of Ilorin \\
\hline & $\begin{array}{l}\text { Obafemi Awolowo University and its Teaching } \\
\text { Hospital }\end{array}$ \\
\hline & Federal Medical Centre in Asaba \\
\hline & Olabisi Onabanjo University Teaching Hospital \\
\hline & Federal Teaching Hospital Abakaliki, Ebonyi State \\
\hline & University of Calabar Teaching Hospital \\
\hline \multirow{2}{*}{ Botswana } & Baylor Children's Clinical Centre of Excellence \\
\hline & Princess Marina Hospital \\
\hline Ghana & Komfo Ankoye Teaching Hospital \\
\hline Ethiopia & Black Lion Hospital \\
\hline Tanzania & St. Francis Referral Hospital \\
\hline Sudan & Abu Se’id Paediatric Hospital \\
\hline Zanzibar & Mnazi mmoja Referral Hospital \\
\hline \multirow{5}{*}{ Uganda } & Makerere University \\
\hline & Mulago Hospital \\
\hline & Gulu Regional Hospital \\
\hline & Kagando Hospital \\
\hline & Rubaga Hospital \\
\hline
\end{tabular}

ongoing discussions on having the program being officially recognized by the University of Nairobi in Kenya. This will add to the PETCA fellowship international credibility and continuation of the program is planned even after expiration of the World Diabetes Foundation grant with tutors from ESPE and ISPAD.

\section{Discussion}

This is the first report on a successful paediatric endocrinology fellowship program in Africa. PETCA is a fellowship program that was launched to specifically equip paediatricians with the knowledge and skills to diagnose and manage childhood endocrinology disorders and diabetes. Africa has inadequate paediatric subspecialist manpower and this concern is not unique to the region [13-15]. In fact, the American Academy of Paediatrics in 2013 reiterated that there is a shortage of paediatric medical subspecialists in USA and the current pool of paediatricians is insufficient to serve the growing need for family-centered care [16]. These sentiments are echoed in Asia and Europe [17, 18]. PETCA is therefore well placed to contribute to the growth of the paediatric workforce pool in Africa and on the global front at large.

A recent report by the Global Paediatric Education Consortium (GPEC) indicates that the presence of a paediatric workforce in a nation can significantly impact the quality of life for children [19]. The PETCA initiative is a concerted effort to address the workforce disparity across Africa. Fiftyfour fellows have graduated from the program since its launch in 2008, from twelve African countries: Botswana, Congo, Ethiopia, Ghana, Kenya, Mauritius, Nigeria, Rwanda, Sudan, Tanzania, Uganda, and Zambia. The fellows are committed to ensuring equitable, affordable, and accessible provision of paediatric healthcare services across all regions as witnessed in the number of clinics that have been set up or strengthened following completion of both phases one and two of the program. Eight clinics have been strengthened, located in Kenya, Tanzania, and Sudan, while 23 clinics have been established in eight countries across Africa, all dedicated to the paediatric endocrinology subspecialty.

During the fellowship, PETCA fellows had the opportunity to diagnose, treat, and create awareness on diabetes and endocrinology disorders. The findings of this report demonstrate that diabetes and obesity were the leading disorders in this setting accounting for $72 \%$ of all cases. Thyroid disorders were the least common among two percent of patient pool. The noncommunicable disease (NCD) epidemic in Africa is fast growing but silent and ignored [20,21]. There is great paucity in the data, especially on the burden and prevalence rates of diseases, because of misdiagnosis, underdiagnosis, and poor health systems infrastructure in most African countries [22]. Nonetheless, diabetes and obesity are recognized as leading causes of mortality and morbidity in children in Africa [23-25]. Therefore, concerted efforts by PETCA to build capacity within the region will translate in a significant reduction in endocrine- and diabetes-linked morbidity and mortality rates which will go a long way in addressing the wide disparity in the quality of life for children around the world $[26,27]$. In addition, this will encourage an increase in investments channeled towards paediatric endocrinology.

Child health needs are unique and complicated as children are constantly developing. Therefore, paediatricians are the best physician specialists to address their health needs. Paediatric endocrinologists are subspecialists with additional focused training in the specialized area of endocrinology. PETCA advocates and caters for the need for paediatric endocrinology subspecialists and these efforts have had a transformational impact on the lives of children in SSA. Practical instruction during the fellowship has allowed actual detection, treatment, and care of patients with complex 
endocrine conditions and diabetes within the training institutions. The expertise required to diagnose and manage the complex child endocrine disorders is not part of routine paediatric training. Hence, building capacity of endocrinology specialists across Africa provides a crucial network base for referrals and consult services for clinicians in tertiary facilities, managing complex disorders. Prompt identification of the disorders and treatment has been shown to have a significant impact as it prevents the detrimental lifelong physical and neurodevelopmental effects for the child [1]. It is therefore very important that the care provided should be by a specialist experienced in paediatric endocrinology management, so as to address the complexity of the evaluation adequately.

PETCA is a sustainable initiative, as the alumni are now taking part as trainers so as to ensure the capacity building efforts, specifically training new fellows, and the successes of the PETCA program will translate to the improvement of the quality and access to specialized healthcare to all children in Sub-Saharan Africa. Overall, PETCA efforts are in line with internationally recognized recommendations and guidelines including the British Society for Paediatric Endocrinology and Diabetes, Australasian Paediatric Endocrine Group, and the Canadian Paediatric Endocrine Group [28-30]. All these are concerned with the management and research that will foster a better understanding of disorders of the endocrine system in children. They each have training opportunities, similar to PETCA, which are in place to ensure that paediatricians are well trained on child endocrinology and diabetes and ensure equity in capacity globally.

\section{Conclusion}

The successes of the PETCA program demonstrate the impact a capacity building and knowledge transfer model can have on a population. PETCA serves as an innovative model to encourage equity in the availability of qualified health care personnel globally. The model provides more training opportunities than would have been available in a developed country. Training on the continent also means all qualified personnel are retained on the continent.

\section{Conflict of Interests}

The authors declare that there is no conflict of interests regarding the publication of this paper.

\section{Acknowledgment}

The PETCA initiative is sponsored by World Diabetes Foundation: Grants nos. WDF 07-263 and WDF 11-609.

\section{References}

[1] M. Zacharin, J. P. Chanoine, F. Cassorla et al., "Promoting excellence in the care of pediatric endocrine diseases in the developing world," Pediatrics, vol. 131, no. 2, pp. e573-e578, 2013.

[2] D. B. Dunger, M. A. Sperling, C. L. Acerini et al., "European Society for Paediatric Endocrinology/Lawson Wilkins Pediatric
Endocrine Society consensus statement on diabetic ketoacidosis in children and adolescents," Pediatrics, vol. 113, no. 2, pp. e133-e140, 2004.

[3] P. Cohen, A. D. Rogol, C. L. Deal et al., "Consensus statement on the diagnosis and treatment of children with idiopathic short stature: a summary of the Growth Hormone Research Society, the Lawson Wilkins Pediatric Endocrine Society, and the European Society for Paediatric Endocrinology Workshop," Journal of Clinical Endocrinology and Metabolism, vol. 93, no. 11, pp. 4210-4217, 2008.

[4] J. Léger, A. Olivieri, M. Donaldson et al., "European society for paediatric endocrinology consensus guidelines on screening, diagnosis, and management of congenital hypothyroidism," Hormone Research in Paediatrics, vol. 81, no. 2, pp. 80-103, 2014.

[5] G. Ocal, "Current concepts in disorders of sexual development," Journal of Clinical Research in Pediatric Endocrinology, vol. 3, no. 3, pp. 105-114, 2011.

[6] F. Chiarelli and M. L. Marcovecchio, "Insulin resistance and obesity in childhood," European Journal of Endocrinology, vol. 159, no. 1, pp. S67-S74, 2008.

[7] A. Kundel, G. B. Thompson, M. L. Richards et al., "Pediatric endocrine surgery: a 20-year experience at the mayo clinic," Journal of Clinical Endocrinology and Metabolism, vol. 99, no. 2, pp. 399-406, 2014.

[8] E. S. Majaliwa, B. E. J. Elusiyan, O. O. Adesiyun et al., "Type 1 diabetes mellitus in the African population: epidemiology and management challenges," Acta Biomedica de l'Ateneo Parmense, vol. 79, no. 3, pp. 255-259, 2008.

[9] G. L. Warne and J. Raza, "Disorders of sex development (DSDs), their presentation and management in different cultures," Reviews in Endocrine and Metabolic Disorders, vol. 9, no. 3, pp. 227-236, 2008.

[10] Kenya National Bureau of Statistics, The 2009 Kenya Population and Housing Census, Kenya National Bureau of Statistics, 2010.

[11] Ministry of Health-Kenya, "Kenya Health Policy 2014-2030," January 2016, https://www.afidep.org/?wpfb_dl=80.

[12] The UN Inter-Agency Group for Child Mortality Estimation, "Kenya: Basic Indicators," 2013, http://www.unicef.org/ infobycountry/kenya_statistics.html.

[13] E. A. Elhalaby, F. A. Uba, E. S. Borgstein, H. Rode, and A. J. W. Millar, "Training and practice of pediatric surgery in Africa: past, present, and future," Seminars in Pediatric Surgery, vol. 21, no. 2, pp. 103-110, 2012.

[14] L. B. Chirdan, E. A. Ameh, F. A. Abantanga, D. Sidler, and E. A. Elhalaby, "Challenges of training and delivery of pediatric surgical services in Africa," Journal of Pediatric Surgery, vol. 45, no. 3, pp. 610-618, 2010.

[15] G. Swingler, M. Hendricks, D. Hall et al., "Can a new paediatric sub-specialty improve child health in South Africa?" South African Medical Journal, vol. 102, no. 9, pp. 738-739, 2012.

[16] R. W. Block, B. P. Dreyer, A. R. Cohen, B. Stapleton, S. L. Furth, and R. L. Bucciarelli, "An agenda for children for the 113th congress: recommendations from the pediatric academic societies," Pediatrics, vol. 131, no. 1, pp. e109-e119, 2013.

[17] A. Rammohan, K. Iqbal, and N. Awofeso, "Reducing neonatal mortality in India: critical role of access to emergency obstetric care," PLoS ONE, vol. 8, no. 3, Article ID e57244, 2013.

[18] J. H. H. Ehrich, A. Tenore, S. del Torso, M. Pettoello-Mantovani, S. Lenton, and Z. Grossman, "Diversity of pediatric workforce and education in 2012 in Europe: a need for unifying concepts or accepting enjoyable differences?" The Journal of Pediatrics, vol. 167, no. 2, pp. 471.e4-476.e4, 2015. 
[19] Global Pediatric Education Consortium, "The Global Pediatric Education Consortium: transforming pediatric training and child health through collaboration," Pediatrics International, vol. 52, no. 4, pp. 684-686, 2010.

[20] M. Naghavi and M. H. Forouzanfar, "Burden of non-communicable diseases in sub-Saharan African in 1990 and 2010: Global Burden of Diseases, Injuries, and Risk Factors Study 2010," October 2015, http://www.thelancet.com/pdfs/journals/ lancet/PIIS0140-6736(13)61349-5.pdf.

[21] S. Dalal, J. J. Beunza, J. Volmink et al., "Non-communicable diseases in sub-Saharan Africa: what we know now," International Journal of Epidemiology, vol. 40, no. 4, pp. 885-901, 2011.

[22] N. P. Steyn, Z. J.-R. McHiza, and A.-P. Kengne, "Future challenges for pediatric diabetes management in developing countries: lessons from Africa," Expert Review of Endocrinology and Metabolism, vol. 10, no. 1, pp. 75-86, 2014.

[23] T. Ngwiri, F. Were, B. Predieri, P. Ngugi, and L. Iughetti, "Glycemic control in Kenyan children and adolescents with Type 1 diabetes mellitus," International Journal of Endocrinology, vol. 2015, Article ID 761759, 7 pages, 2015.

[24] S. K. Muthuri, C. E. Francis, L.-J. M. Wachira et al., "Evidence of an overweight/obesity transition among school-aged children and youth in Sub-Saharan Africa: a systematic review," PLoS ONE, vol. 9, no. 3, Article ID e92846, 2014.

[25] S. P. Reddy, K. Resnicow, S. James et al., "Rapid increases in overweight and obesity among South African adolescents: comparison of data from the South African national youth risk behaviour survey in 2002 and 2008," American Journal of Public Health, vol. 102, no. 2, pp. 262-268, 2012.

[26] United Nations Children's Fund, The State of the World's Children 2009, UNICEF, New York, NY, USA, 2009.

[27] World Health Organization, World Health Statistics 2008, WHO, Geneva, Switzerland, 2008.

[28] British Society for Paediatric Endocrinology, "Education and Training," October 2015, http://www.bsped.org.uk/training/ training_secondary.aspx.

[29] Australasian Paediatric Endocrine Group, "Fellows \& Training," October 2015, http://www.apeg.org.au/Default.aspx?tabid=111.

[30] Canadian Pediatric Endocrine Group, "Fellowships and awards," October 2015, http://www.cpeg-gcep.net/content/fellowshipsawards. 


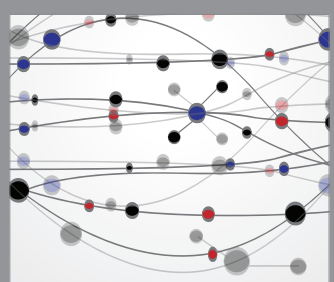

The Scientific World Journal
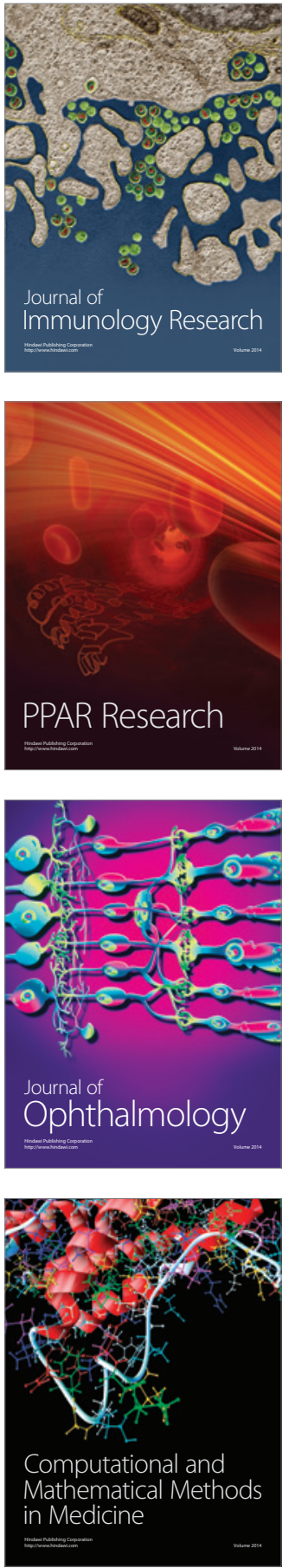

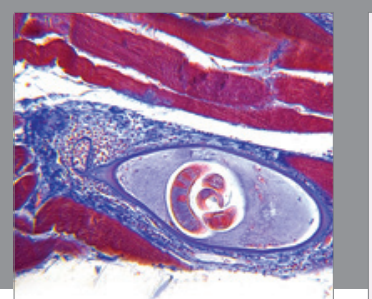

Gastroenterology Research and Practice

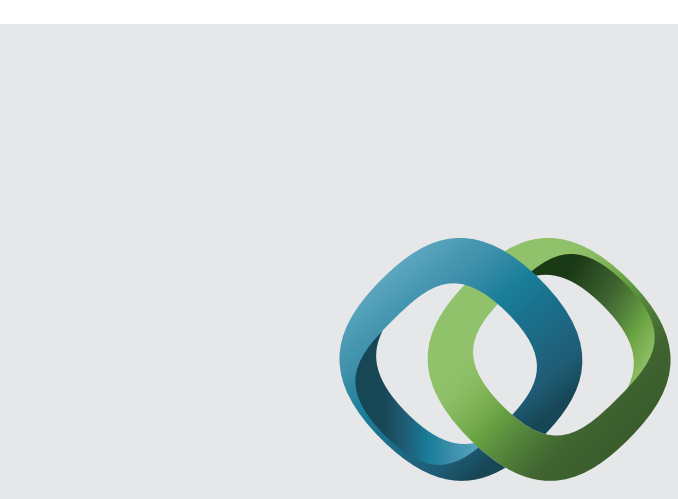

\section{Hindawi}

Submit your manuscripts at

http://www.hindawi.com
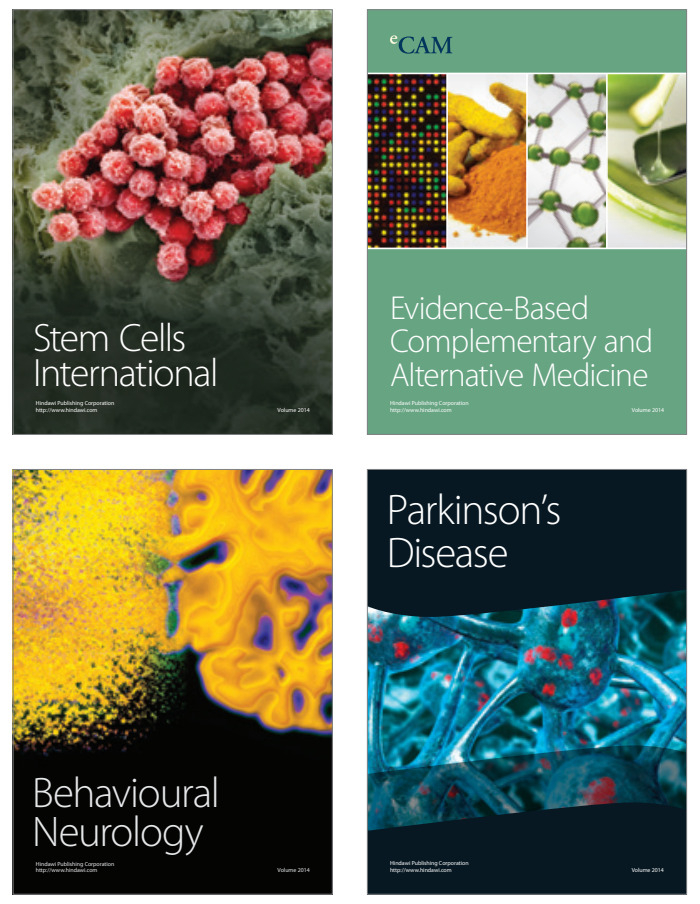
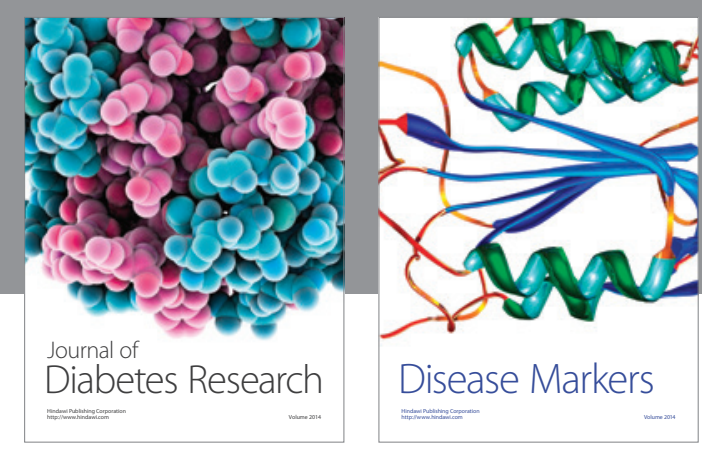

Disease Markers
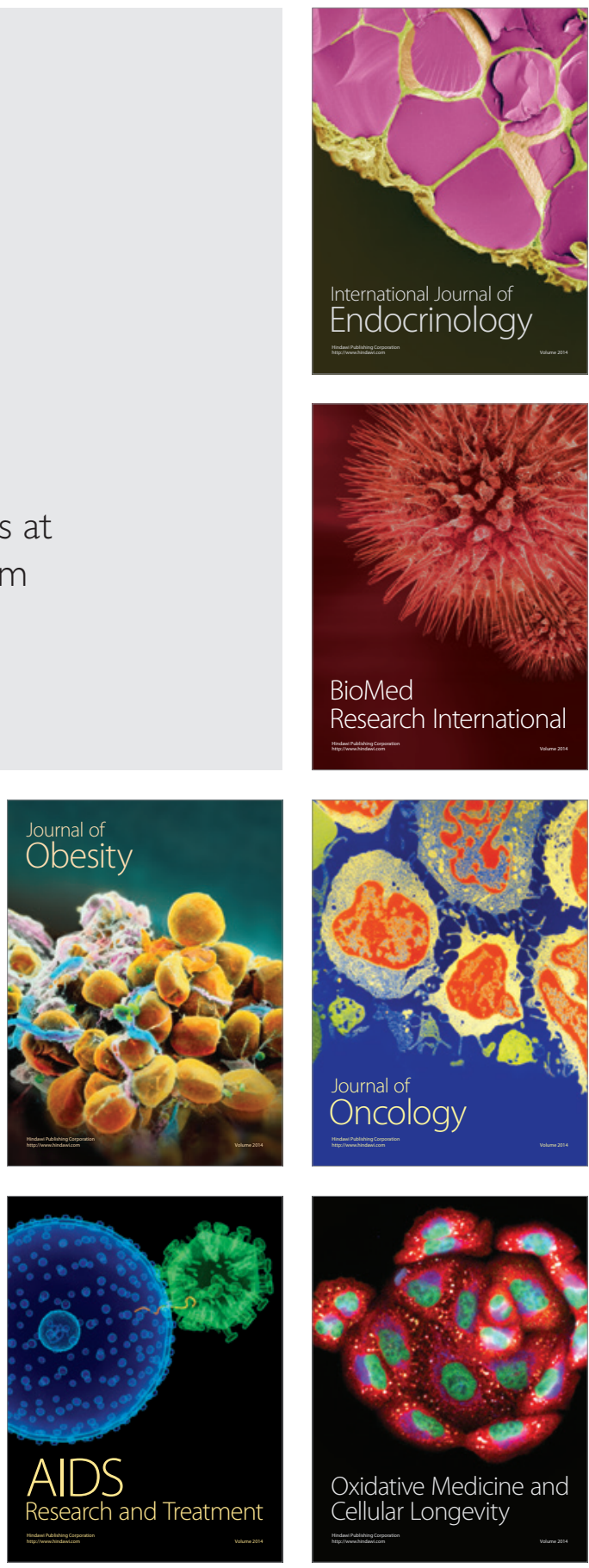